\title{
Intravenous pulses of methylprednisolone for infants with severe bronchopulmonary dysplasia and respiratory support after 3 months of age
}

Elodie Billion, MD, Pediatric Pulmonology, University Hospital Necker-Enfants Malades, AP-HP, Paris, France;

Alice Hadchouel, MD, PhD, Pediatric Pulmonology, University Hospital Necker-Enfants Malades, AP-HP, Paris, France; Paris Descartes University, Paris, France

Nicolas Garcelon, MD, PhD, Institut Imagine, Paris Descartes Université Paris DescartesSorbonne Paris Cité, Paris, France ; INSERM, Centre de Recherche des Cordeliers, UMR 1138 Equipe 22 ; Paris Descartes University, Paris, France

Christophe Delacourt, MD, PhD, Pediatric Pulmonology, University Hospital Necker-Enfants Malades, AP-HP, Paris, France; Paris Descartes University, Paris, France

David Drummond, MD, PhD, Pediatric Pulmonology, University Hospital Necker-Enfants Malades, AP-HP, Paris, France; INSERM, Centre de Recherche des Cordeliers, UMR 1138 Equipe 22; Paris Descartes University, Paris, France

\section{Corresponding author}

David Drummond, MD, PhD. Department of Pediatric Pulmonology, Necker-Enfants Malades Hospital, 149 rue de Sèvres, 75015 Paris. Phone number: + 3314449 48 48, Email: david.drummond@aphp.fr

Short title: Pulses of methylprednisolone for bronchopulmonary dysplasia

\section{Funding Source: none}

Conflict of Interest: The authors have no conflicts of interest to disclose.

All authors approved the final manuscript as submitted and agree to be accountable for all aspects of the work.

Reprints: No reprints will be ordered.

Keywords: mechanical ventilation; non-invasive ventilation; oxygen therapy; corticosteroids ;

Manuscript 3250 words. Abstract 243 words. Tables: 2. Figures: 3.

This article contains supplementary material.

\section{List of abbreviations:}

BPD: bronchopulmonary dysplasia

FiO2: Fraction of inspired oxygen

GA: gestational age

IV: intravenous

NIV: non invasive ventilation 


\begin{abstract}
Introduction. There are few published data on the efficacy of systemic corticosteroids in preterm infants with very severe forms of bronchopulmonary dysplasia (BPD), requiring respiratory support after 3 months of age. The aim of this study was to report the use of pulses of methylprednisolone in this population and its consequences on the level of respiratory support.
\end{abstract}

Methods. This retrospective monocentre study included infants over three months of age with severe BPD who received at least one pulse of methylprednisolone $\left(300 \mathrm{mg} / \mathrm{m}^{2} /\right.$ day IV over three days). The primary outcome was the evolution of the pulmonary severity score (PSS) during the three months preceding and the five months following the first pulse. The evolution of the median PSS over time was analysed using linear segmented regression for interrupted time series.

Results. Ten infants were included. During the three months preceding the first pulse, a significant increase in the median PSS was observed $(\mathrm{p}=0.01)$, followed by a progressive decrease during the five months after administration of the first pulse $(\mathrm{p}<0.01)$. Greater effects were observed in more severe infants requiring mechanical or non-invasive ventilation than in those receiving supplemental oxygen through nasal cannula.

Conclusion. High-dose IV pulses of methylprednisolone were associated with a decrease in the level of respiratory support required by infants with very severe forms of BPD, with a greater effect in those on mechanical or non-invasive ventilation. Further studies are warranted to confirm these preliminary results and assess the long-term safety of this therapy. 


\section{Intravenous pulses of methylprednisolone for infants with severe bronchopulmonary dysplasia and respiratory support after 3 months of age}

\section{Introduction}

Preterm birth interferes with correct alveolar development, with larger and fewer alveoli and decreased pulmonary capillary density, which are the hallmarks of bronchopulmonary dysplasia $(\mathrm{BPD})^{1-3}$. These pathologic findings can clinically manifest as gas exchange abnormalities, with infants requiring supplemental oxygen for hypoxemia and/or ventilatory support for hypercarbia during their first weeks of life. Infants still requiring $>0.30$ fraction of inspired oxygen (FiO2) and/or positive pressure ventilation or continuous positive airway pressure at 36 weeks' postmenstrual age are considered to have a severe $\mathrm{BPD}^{4}$. The EPIPAGE2 cohort study conducted in France in 2011 found that severe BPD concerned 25\% of infants born before 27 weeks of gestational age $(\mathrm{GA})^{5}$. Among these patients, a small proportion still require respiratory support after three months of age. At that time, they often have been transferred from neonatal intensive care to paediatric intensive care units or pulmonology departments.

Because inflammation plays a prominent role in the pathogenesis of BPD, systemic steroids have been used as anti-inflammatory agents to alter the course of lung disease in premature infants $^{6,7}$. Administered early (0-7 days of age), short courses of dexamethasone and hydrocortisone were associated with decreased rates of BPD and death at 36 weeks' postmenstrual age ${ }^{8}$. These benefits were mitigated in infants who received dexamethasone by an increased incidence of cerebral palsy ${ }^{9}$, which was not observed with hydrocortisone ${ }^{10}$. Administered later, between 7 and 28 days of age, systemic steroids were associated with 
reductions in the rates of BPD or death at 36 weeks' postmenstrual age, failure to extubate, discharge on home oxygen, but not with neurological impairment ${ }^{11}$. A trend towards increased risks of infection, gastrointestinal bleeding and retinopathy of prematurity was reported ${ }^{11}$. The administration of systemic steroids after 2 months of age for infants with very severe BPD still requiring oxygen therapy or ventilatory support remains understudied. Bhandari et al. described the efficacy of a two-week tapering course of prednisolone in infants with mild to moderate BPD and a mean age of 2.5 months ${ }^{12}$. Of the 131 infants who received treatment, 82 $(63 \%)$ were successfully weaned off oxygen. Linafelter et $\mathrm{al}^{13}$ reported the use of prednisolone therapy in a population of 43 infants with severe BPD and a median age of 3.5 months. An extended course of prednisolone, with a median duration of 67 days, was associated with modest short-term improvement in oxygenation, but impaired linear growth.

At our center, clinical practitioners in both pediatric intensive care and pediatric pulmonology have developed the practice of trying high dose of intravenous (IV) methylprednisolone pulses in infants aged 3 months or more with very severe BPD requiring mechanical ventilation, noninvasive ventilation (NIV), or oxygen therapy associated with repeated severe exacerbations.

The objective of this study was to describe the evolution of the levels of respiratory support required by these infants with very severe BPD following the initiation of IV methylprednisolone pulses.

\section{Material and methods}

\section{Study design and population}

In this retrospective single centre study, we used the clinical data warehouse of the university hospital Necker-Enfants Malades (Paris, France) containing about 400,000 patients to identify our population ${ }^{14}$. Patients were included if they fulfilled the following criteria: they were born 
preterm ( $\leq 37$ weeks of GA) between January 2010 and December 2018, had a diagnosis of BPD defined as the need for supplemental oxygen (>0.30 FiO2) and/or ventilatory support at 36 weeks of post-menstrual age, were still requiring supplemental oxygen and/or ventilatory support after three months of age, and had received at least one IV pulse of high-dose methylprednisolone. Control patients responding to the same inclusion criteria except that they did not receive methylprednisolone IV pulses were also included. Methylprednisolone IV pulses were administered at the dose of $300 \mathrm{mg} / \mathrm{m} 2 /$ day for three days. At the discretion of the physician, methylprednisolone pulses could be repeated with a minimum interval of four weeks. The study was approved by the Institutional Review Board of the French learned society for respiratory (CEPRO 2019-015). Parents were informed of the study and provided oral consent for the use of de-identified data from their children's health electronic records.

\section{Outcomes}

The primary outcome was the evolution of the median pulmonary severity score (PSS) between the three months preceding and the five months following the first pulse of methylprednisolone. The PSS is a validated scoring system that considers respiratory support, FiO2, and respiratory treatments to estimate the severity of lung disease in preterm infants ${ }^{15}$. It is expressed as the fraction of inspired oxygen $($ Fio2 $) \times$ (support) + (medications), where Fio2 is the actual or "effective" (for nasal cannula) Fio2; support is 2.5 for a ventilator, 1.5 for nasal continuous positive airway pressure, or 1.0 for nasal cannula or spontaneous ventilation; and medications is 0.20 for systemic steroids for bronchopulmonary dysplasia, 0.10 each for regular diuretics or inhaled steroids, and 0.05 each for methylxanthines or intermittent diuretics. The scores could range from 0.21 to 2.95 .

Secondary outcomes included the evolution of PSS on an individual basis, and adverse effects associated with corticosteroids treatments. These adverse effects included the impact of pulses 
on the weight and height. Weight and height z-scores adjusted by birth term were measured three months before the first pulse, at the time of the first pulse, one month after the first pulse and three months after the last pulse. Episodes of infection, hypertension, and/or hyperglycaemia that occurred during the methylprednisolone pulses were also recorded.

\section{Data collection}

Data were obtained from the electronic health records of the infants and included antenatal data (in utero exposure to tobacco, history of oligoamnios, antenatal steroids), neonatal data (gender, gestational age, birth weight, history of hyaline membrane disease, pulmonary hypertension, sepsis, necrotizing enterocolitis, duration of mechanical ventilation, NIV), infant's data at the time of starting the pulse(s) of methylprednisolone (age, comorbidities, respiratory support) and during follow-up (respiratory support, weight and length converted to z-scores). Frequency of other potential adverse effects was also collected.

\section{Statistics}

Descriptive statistics such as mean and standard deviations, median and interquartile ranges, and proportions were used to summarize the data. A linear segmented regression analysis of interrupted time series was used for the evaluation of our primary outcome ${ }^{16}$. Through this method, it is possible to measure the effect of an event (here the first pulse of methylprednisolone), on a series of measures repeated over time (here the PSS). The set of measures is divided into two segments, before and after the intervention. Each segment is defined by two parameters: its level (the value of the series at the beginning of the period) and its trend (its slope). The principle of segmented regression analysis is to examine the changes in level and/or trend that follow an intervention, and can be specified as follows:

$$
Y t=\beta 0+\beta 1 \text { Time }_{t}+\beta 2 \text { Intervention }_{t}+\beta 3 \text { Time after intervention } t+e_{t}
$$


$\beta_{0}$ estimates the baseline level of the outcome, $\beta_{1}$ is the trend of the first segment, $\beta_{2}$ is the change of level of the outcome just after the intervention and $\beta_{3}$ estimates the change in the trend after the intervention compared to the trend before intervention $\left(\beta_{1}\right)$. The error term et represents the random variability not explained by the model. A search for autocorrelation by a Durbin-Watson test completed the validation of this method.

Significance was set at $\mathrm{p} \leq 0.05$. Analyses were performed with SAS version 9.3 software (SAS Institute, Inc, Cary, NC), and graphics with GraphPad prism software v5.03 (La Jolia, California).

\section{Results}

Ten infants who received methylprednisolone IV pulses were identified from the clinical data warehouse. Their antenatal and neonatal characteristics are presented in Table 1. All these infants required mechanical ventilation during their neonatal life. Infants who received pulses of methylprednisolone had their first pulse at a median age (IQ1-3) of 6 months (6-9), specifically at a median age of 6 months (6-6) for those who were on mechanical ventilation or NIV, and 9 months (6-15) for those who were on nasal cannula. Their characteristics at the starting of the methylprednisolone pulse(s) are presented in Table 2. All pulses of methylprednisolone IV were administered at a dose of $300 \mathrm{mg} / \mathrm{m} 2 /$ day over four to eight hours, for three days. The median number of pulses (IQ1-3) administered per patient was $2.5(1-4)$, with a minimum of one and a maximum of nine, and the interval between two pulses was four weeks.

Eight of the 10 infants included had received at least one course of oral corticosteroid therapy in the month prior to their first pulse. Of these, six were considered corticosteroid-dependent by their medical team. Details regarding the molecule, dose and timing of the oral courses 
administered are provided in the supplemental Table S1. For the 10 infants, the median (IQ13) number of courses of oral corticosteroid therapy administered during the 3 months preceding the first IV pulse of methylprednisolone was 1 (1-2), for a median duration of 14 days (8-24). Six infants who responded to the same inclusion criteria except that they did not receive any IV pulse of methylprednisolone were identified. All were on nasal cannula and constituted a control group for the five infants who received IV pulse(s) of methylprednisolone for $\mathrm{O} 2$ weaning. These controls were born at a lower gestation age, with a lower birthweight, and had a longer duration of mechanical ventilation compared to the infants who received IV pulses (Table 1).

\section{Evolution of the level of respiratory support after methylprednisolone pulse(s)}

The evolution of the level of respiratory support assessed by the PSS during the three months preceding and the five months following the administration of the first methylprednisolone pulse is illustrated in Figure 1A. Before the starting of the first methylprednisolone pulse, there was a slight but regular increase in the median PSS of the infants included, whereas it was the reverse after, with a regular decrease in the median PSS following the first pulse. The linear segmented regression analysis of interrupted time series confirmed a statistically significant increase in median PSS during the three months preceding the first pulse (coefficient $\beta 1=0.06$; $\mathrm{p}=0.01$ ), a non-significant decrease just after the introduction of the first pulse (coefficient $\beta 2=-$ $0.0 ; \mathrm{p}=0.98$ ), and finally a statistically significant change in slope, with inversion of the slope following the introduction of the first pulse (coefficient $\beta 3=-0.10 ; p=0.001$ ). The value of Durbin Watson test was inconclusive (2.71). The decrease in PSS following the starting of the IV pulses of methylprednisolone was greater in the five patients who required mechanical ventilation or NIV than in the five patients who required supplemental oxygen through nasal cannula (Figure 1B and 1C). 
Two patients (patients 1 and 2) received methylprednisolone pulses with the objective of weaning them off mechanical ventilation (Figure 2). Both patients were weaned from mechanical ventilation within 15 days after their first pulse, with a NIV relay. Patient 1 received two additional pulses to wean him off NIV, without success. Three other patients (patients 3-5) received methylprednisolone pulses with the objective of weaning them off NIV 24h/24 (Figure 2). Patient 3 was weaned off NIV after two pulses, patient 4 kept NIV only $12 \mathrm{~h} / 24$ (at night) after the first pulse and was definitely weaned off after the third pulse. Patient 5 kept NIV only $12 \mathrm{~h} / 24$ (at night) after the third pulse and was weaned off after 5 pulses.

The evolution of the median PSS of the infants who required supplemental oxygen on nasal cannula is illustrated in Figure 3 (All patients with nasal cannula), with the evolution of those who received IV pulses of methylprednisolone and of controls. No statistical test was performed due to the small sample size of each group ( $n=5$ and $n=6$, respectively), but it seemed that infants who received methylprednisolone IV pulse(s) had increasing PSS before the starting of the pulses and higher PSS at the start of the pulses compared to the six infants belonging to the control group who had decreasing or stable PSS at the same ages, and lower PSS values. The individual PSS evolution for each infant who received IV pulse(s), compared to the median PSS of the six controls at the same ages, is also presented in Figure 3 (Patients 6-10). Beside the higher respiratory morbidity of each infant who received IV pulse(s) reflected by higher PSS, the changes in PSS appeared to parallel those of control infants. Except patient 9, all the patients who received IV pulses of methylprednisolone were weaned off their oxygen therapy after one or two pulses.

\section{Safety of methylprednisolone pulse(s)}


The median weight z-scores (IQ1-3) measured three months before the first pulse, at the time of the first pulse, one month after the first pulse and three months after the last pulse did not differ significantly with values of $-1.5(-2.7 ;-1.0) ;-2.3(-2.6 ;-1.8) ;-1.7(-3.2 ;-1.5)$ and $-1.5(-$ $2.2 ;-0,2)$, respectively $(\mathrm{p}=0.64)$. The median height $\mathrm{z}$-scores (IQ1-3) did not differ significantly either with values of $-2.0(-3.5 ;-1.5) ;-2.0(-2.5 ;-1.0) ;-1.25(-3.0 ;-0.6)$; and $-2.0(-3.06 ;-0.60)$, respectively $(\mathrm{p}=0.60)$.

Other adverse outcomes included adrenal insufficiency in four infants after the pulses, including two infants with pre-existing adrenal insufficiency before the start of the pulses, high blood pressure requiring a pause during the administration of the first two pulses in an infant (patient 10), and agitation during the second pulse of patient 9. No hyperglycaemia was observed.

\section{Discussion}

In this retrospective monocentre study, the administration of IV methylprednisolone pulses at a dose of $300 \mathrm{mg} / \mathrm{m}^{2} /$ day over three days to infants aged more than three months with severe BPD was associated with improvements in the PSS of those requiring mechanical ventilation or NIV, whereas the effect in those with nasal cannula for supplemental oxygen was more questionable.

For the two infants who were critically ill and required mechanical ventilation, the IV methylprednisolone pulses were provided as a rescue treatment. Both were weaned off from mechanical ventilation rapidly after the start of the pulses, with a NIV relay. The effect of corticosteroids on hastening weaning from mechanical ventilation had been reported in preterms with BPD in neonatal intensive care units, but not in older infants with BPD aged 
more than 3 months ${ }^{11}$. The improvements observed after the start of high-dose IV methylprednisolone in these two infants aged 6 and 7 months advocates for a persisting lung inflammation linked to their severe BPD and acutely exacerbated by mechanical ventilation, that was counteracted by this anti-inflammatory treatment ${ }^{17}$. Two of the three infants who required chronic NIV in our study also seemed to improve after the IV pulse(s) of methylprednisolone. Similarly to our study, Linafeter et al reported the outcomes of 43 infants with severe BPD requiring mechanical ventilation or NIV at a median age of 3.5 months, who received tapering course of systemic corticosteroids ${ }^{13}$. Prednisone or methylprednisolone was administered either orally or IV, at a lower dose than in our study $(0.5-2 \mathrm{mg} / \mathrm{kg} / \mathrm{day})$ and for a median duration of 67 days (range 31 to 406 days). They observed a significant decrease in the PSS mainly attributable to improvement in $\mathrm{FiO} 2$ one week after the initiation of the treatment. These results were consistent with ours, supporting an effect of systemic corticosteroids on respiratory outcomes of infants with severe BPD, even when administered lately, after the first weeks of life.

By contrast, the effect of the IV pulses of methylprednisolone on the PSS of infants who required supplemental oxygen through nasal cannula was less clear, especially when compared to the natural evolution of the PSS scores of the six controls included. Bhandari et al. reported the effects of prednisolone administered in infants aged 2.5 months on average and still requiring oxygen therapy due to severe $\mathrm{BPD}^{12}$. Oral prednisolone was administered at the dose of $2 \mathrm{mg} / \mathrm{kg}$ for five days and then gradually tapered over ten days. Of the 131 infants who received treatment, $82(63 \%)$ were successfully weaned off oxygen. By contrast, in our population, only two out of five infants could be weaned off their oxygen after a single pulse of IV methylprednisolone of $300 \mathrm{mg} / \mathrm{m} 2 /$ day for three days. This is explained by the greater severity of our population who did not respond significantly to several courses of oral steroids before the initiation of IV pulses of methylprednisolone and still required oxygen at a median 
age of 9 months. Nevertheless, the benefit/risk ratio seemed less favourable in this population of infants on nasal cannula compared to the benefit/risk ratio observed for infants on mechanical ventilation or NIV, especially when comparing to the natural evolution of controls and taking in account potential side-effects such as steroid induced adrenal insufficiency.

This study does not address the question of the choice of the best molecule between the different corticosteroids, nor its best administration route. There were three reasons why we chose to use high-dose IV pulses of methylprednisolone. Firstly, most infants had already received several courses of oral corticosteroids with insufficient results, and high-dose IV pulses appeared as a second-line treatment to attempt a weaning from their respiratory support. Both the increase in doses and the use of the intravenous route could explain the greater efficacy observed with the IV pulses of methylprednisolone compared to the oral courses of corticosteroids. The pharmacokinetics of corticosteroids in infants born preterm remain poorly studied ${ }^{18}$, but in older children there is a marked variability in absorption and metabolism of oral prednisone ${ }^{19}$, and at the same dose, an oral course can result in a decreased bioavailability of the corticosteroid compared to an IV course ${ }^{20}$. Secondly, for infants mechanically ventilated, systemic steroids were considered life-saving measures, and high-dose IV pulses were expected to be associated with the most rapid and significant improvements. Safety was the third consideration to choose between high-dose, monthly, IV pulses, and daily oral corticosteroids. Imbasciati et al conducted a study in patients with nephrotic syndrome which compared the administration of three-day pulses of methylprednisolone followed by low doses of oral corticosteroids for six months, to one month of treatment with high-dose oral corticosteroids followed by five months of oral corticosteroids at low dose $\mathrm{e}^{21}$. They found a reduction in the adverse effects observed in the group who received the pulses of methylprednisolone. Similarly, we did not find a concerning impact of the pulses of methylprednisolone on the linear growth of the infants we 
included whereas Linafelter et al., who used extended courses of oral prednisone, did observe impaired linear growth after four weeks of continuous therapy by prednisolone ${ }^{13}$.

The main limitations of this study are its retrospective nature and its small sample size that preclude the establishment of a causal link between the improvements in the levels of respiratory support observed and the administration of methylprednisolone pulses. Infants with severe BPD still requiring respiratory support after three months of age are rare, explaining the small sample size. Another major limitation is that our study lacks a full assessment of longterm neurological outcomes, whereas there is a large body of evidence that both severe BPD and corticosteroids can be associated with poor neurological outcomes in children born preterm $^{22-25}$. However, both the use of methylprednisolone, which is safer than dexamethasone regarding neurological outcomes ${ }^{26}$, and its late administration ${ }^{27}$, after three months of age, decrease the likelihood of adverse neurological outcomes in the infants we included.

\section{Conclusion}

The results of this retrospective study suggest that the administration of IV methylprednisolone pulses to infants over 3 months of age with severe BPD is associated with a positive benefit/risk ratio in the most severe ones requiring mechanical ventilation or NIV, whereas the effect was less clear in those receiving supplemental oxygen only. Further studies are needed to confirm these preliminary results. 


\section{References}

1. Halliday HL. Update on Postnatal Steroids. NEO 2017;111(4):415-422.

2. Sobonya RE, Logvinoff MM, Taussig LM, Theriault A. Morphometric Analysis of the Lung in Prolonged Bronchopulmonary Dysplasia. Pediatric Research 1982;16(11):969-972.

3. Husain AN, Siddiqui NH, Stocker JT. Pathology of arrested acinar development in postsurfactant bronchopulmonary dysplasia. Human Pathology 1998;29(7):710-717.

4. Ehrenkranz RA, Walsh MC, Vohr BR, Jobe AH, Wright LL, Fanaroff AA, Wrage LA, Poole K. Validation of the National Institutes of Health Consensus Definition of Bronchopulmonary Dysplasia. Pediatrics 2005;116(6):1353-1360.

5. Ancel P-Y, Goffinet F, Kuhn P, Langer B, Matis J, Hernandorena X, Chabanier P, JolyPedespan L, Lecomte B, Vendittelli F, et al. Survival and Morbidity of Preterm Children Born at 22 Through 34 Weeks' Gestation in France in 2011: Results of the EPIPAGE-2 Cohort Study. JAMA Pediatr 2015;169(3):230-238.

6. Hadchouel A, Franco-Montoya M-L, Delacourt C. Altered lung development in bronchopulmonary dysplasia. Birth Defects Research Part A: Clinical and Molecular Teratology 2014;100(3):158-167.

7. Lopez E, Jarreau P-H. Inflammation et dysplasie bronchopulmonaire. Med Sci (Paris) 2013;29(10):823-825.

8. Baud O, Maury L, Lebail F, Ramful D, El Moussawi F, Nicaise C, Zupan-Simunek V, Coursol A, Beuchée A, Bolot P, et al. Effect of early low-dose hydrocortisone on survival without bronchopulmonary dysplasia in extremely preterm infants (PREMILOC): a doubleblind, placebo-controlled, multicentre, randomised trial. The Lancet 2016;387(10030):18271836.

9. Shinwell ES, Karplus M, Reich D, Weintraub Z, Blazer S, Bader D, Yurman S, Dolfin T, Kogan A, Dollberg S, et al. Early postnatal dexamethasone treatment and increased incidence of cerebral palsy. Archives of Disease in Childhood - Fetal and Neonatal Edition 2000;83(3):F177-F181.

10. Baud O, Trousson C, Biran V, Leroy E, Mohamed D, Alberti C. Two-year neurodevelopmental outcomes of extremely preterm infants treated with early hydrocortisone: treatment effect according to gestational age at birth. Archives of Disease in Childhood - Fetal and Neonatal Edition 2019;104(1):F30-F35.

11. Doyle LW, Cheong JL, Ehrenkranz RA, Halliday HL. Late (> 7 days) systemic postnatal corticosteroids for prevention of bronchopulmonary dysplasia in preterm infants Cochrane Neonatal Group, editor. Cochrane Database of Systematic Reviews 2017 Oct 24 [accessed 2020 Jun 8]. http://doi.wiley.com/10.1002/14651858.CD001145.pub4

12. Bhandari A, Schramm CM, Kimble C, Pappagallo M, Hussain N. Effect of a Short Course of Prednisolone in Infants With Oxygen-Dependent Bronchopulmonary Dysplasia. Pediatrics 2008;121(2):e344-e349. 
13. Linafelter A, Cuna A, Liu C, Quigley A, Truog WE, Sampath V, Oschman A. Extended course of prednisolone in infants with severe bronchopulmonary dysplasia. Early Human Development 2019;136:1-6.

14. Garcelon N, Neuraz A, Salomon R, Faour H, Benoit V, Delapalme A, Munnich A, Burgun A, Rance B. A clinician friendly data warehouse oriented toward narrative reports: Dr. Warehouse. Journal of Biomedical Informatics 2018;80:52-63.

15. Madan A, Brozanski BS, Cole CH, Oden NL, Cohen G, Phelps DL. A Pulmonary Score for Assessing the Severity of Neonatal Chronic Lung Disease. Pediatrics 2005;115(4):e450 e457.

16. Wagner AK, Soumerai SB, Zhang F, Ross-Degnan D. Segmented regression analysis of interrupted time series studies in medication use research. Journal of Clinical Pharmacy and Therapeutics 2002;27(4):299-309.

17. Papagianis PC, Pillow JJ, Moss TJ. Bronchopulmonary dysplasia: Pathophysiology and potential anti-inflammatory therapies. Paediatric Respiratory Reviews 2019;30:34-41.

18. Lugo RA, Nahata MC, Menke JA, McClead E. Pharmacokinetics of dexamethasone in premature neonates. Eur J Clin Pharmacol 1996;49(6):477-483.

19. Green OC, Winter RJ, Kawahara FS, Phillips LS, Lewy PR, Hart RL, Pachman LM, Lietman PS. Pharmacokinetic studies of prednisolone in children: Plasma levels, half-life values, and correlation with physiologic assays for growth and immunity. The Journal of Pediatrics 1978;93(2):299-303.

20. Rouster-Stevens KA, Gursahaney A, Ngai K, Daru JA, Pachman LM. Pharmacokinetic study of oral prednisolone compared with intravenous methylprednisolone in patients with juvenile dermatomyositis. Arthritis Care \& Research 2008;59(2):222-226.

21. Imbasciati E, Gusmano R, Edefonti A, Zucchelli P, Pozzi C, Grassi C, Volpe MD, Perfumo F, Petrone P, Picca M. Controlled trial of methylprednisolone pulses and low dose oral prednisone for the minimal change nephrotic syndrome. Br Med J (Clin Res Ed) 1985;291(6505):1305-1308.

22. Drummond D, Hadchouel A, Torchin H, Rozé J-C, Arnaud C, Bellino A, Couderc L, Marret S, Mittaine M, Pinquier D, et al. Educational and health outcomes associated with bronchopulmonary dysplasia in 15-year-olds born preterm Baud O, editor. PLoS ONE 2019;14(9):e0222286.

23. Barrington KJ. The adverse neuro-developmental effects of postnatal steroids in the preterm infant: a systematic review of RCTs. BMC Pediatrics 2001;1(1):1.

24. Murphy BP, Inder TE, Huppi PS, Warfield S, Zientara GP, Kikinis R, Jolesz FA, Volpe JJ. Impaired Cerebral Cortical Gray Matter Growth After Treatment With Dexamethasone for Neonatal Chronic Lung Disease. Pediatrics 2001;107(2):217-221.

25. Yeh TF, Hsieh WS. Outcomes at School Age after Postnatal Dexamethasone Therapy for Lung Disease of Prematurity. The New England Journal of Medicine 2004:10. 
26. André P, Thébaud B, Odièvre MH, Razafimahefa H, Zupan V, Dehan M, LacazeMasmonteil T. Methylprednisolone, an alternative to dexamethasone in very premature infants at risk of chronic lung disease. Intensive Care Med 2000;26(10):1496-1500.

27. Papile L-A, Tyson JE, Stoll BJ, Wright LL, Donovan EF, Bauer CR, Krause-Steinrauf H, Verter J, Korones SB, Lemons JA, et al. A Multicenter Trial of Two Dexamethasone Regimens in Ventilator-Dependent Premature Infants. New England Journal of Medicine 1998;338(16):1112-1119. 
Figures

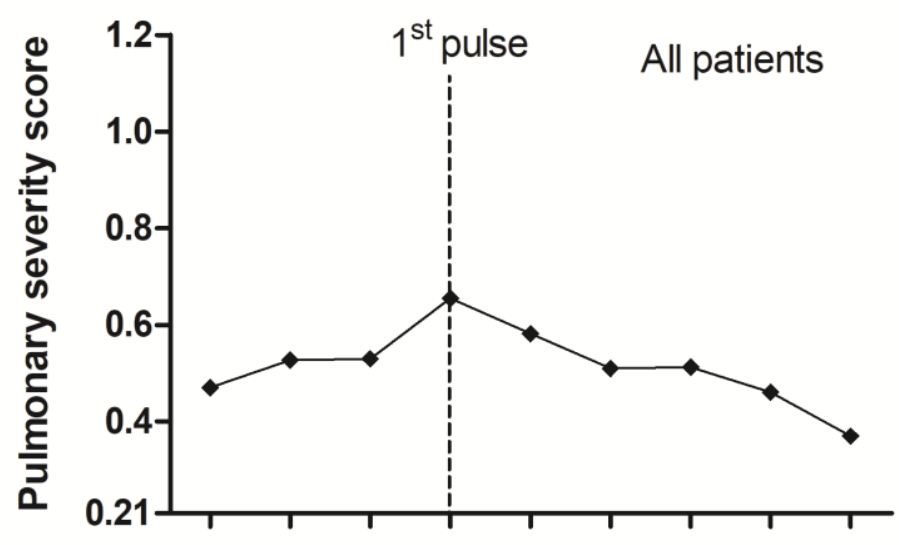

A.
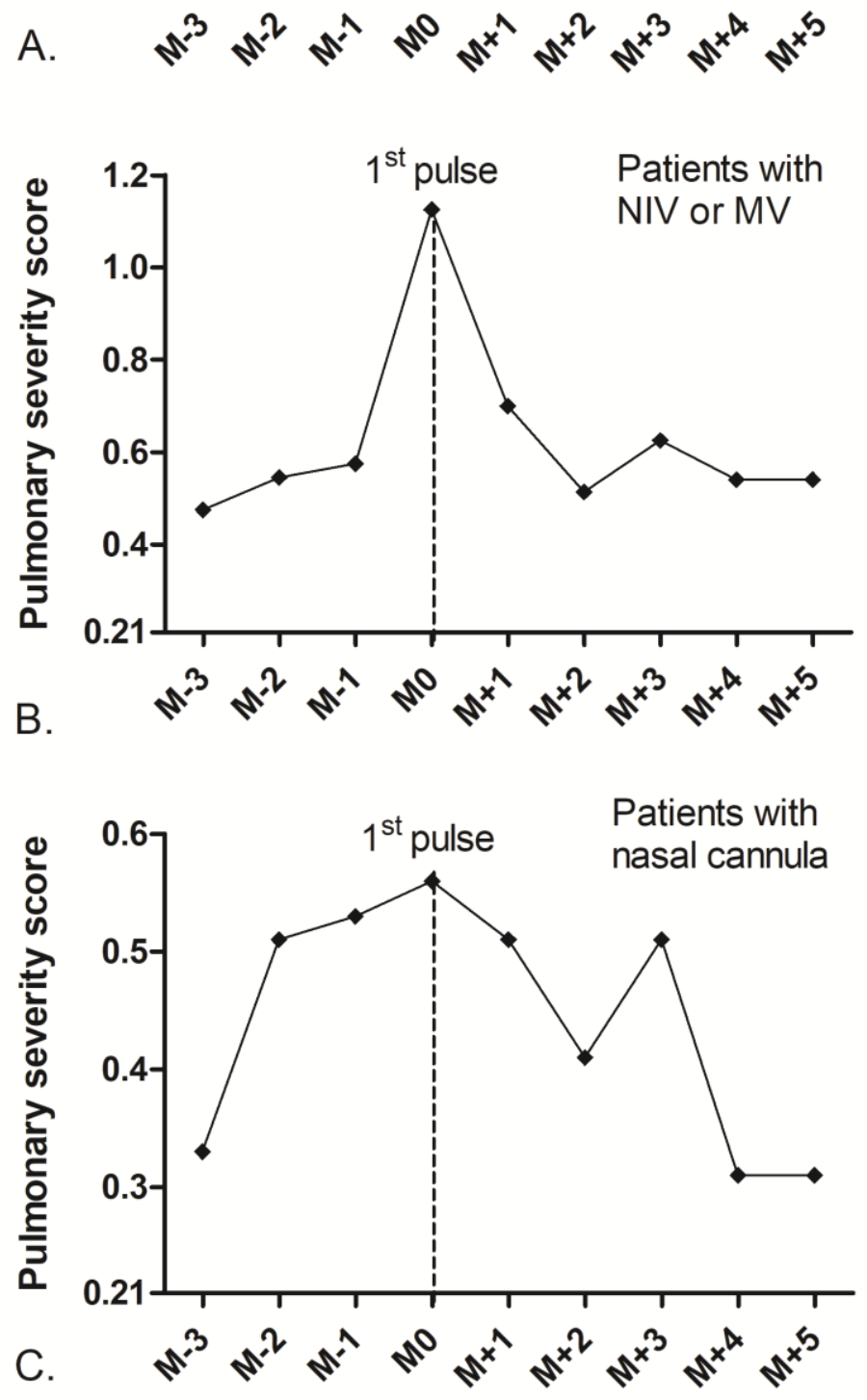

Figure 1: Evolution of the median pulmonary severity scores during the three months before and five months after the first pulse of methylprednisolone.

Legend: The evolution of the pulmonary severity scores is presented for all patients (A, $\mathrm{n}=10$ ), and then specifically for patients on mechanical ventilation (MV) or non-invasive ventilation (NIV) $(B, n=5)$, and patients on nasal cannula $(C, n=5)$. M: month 

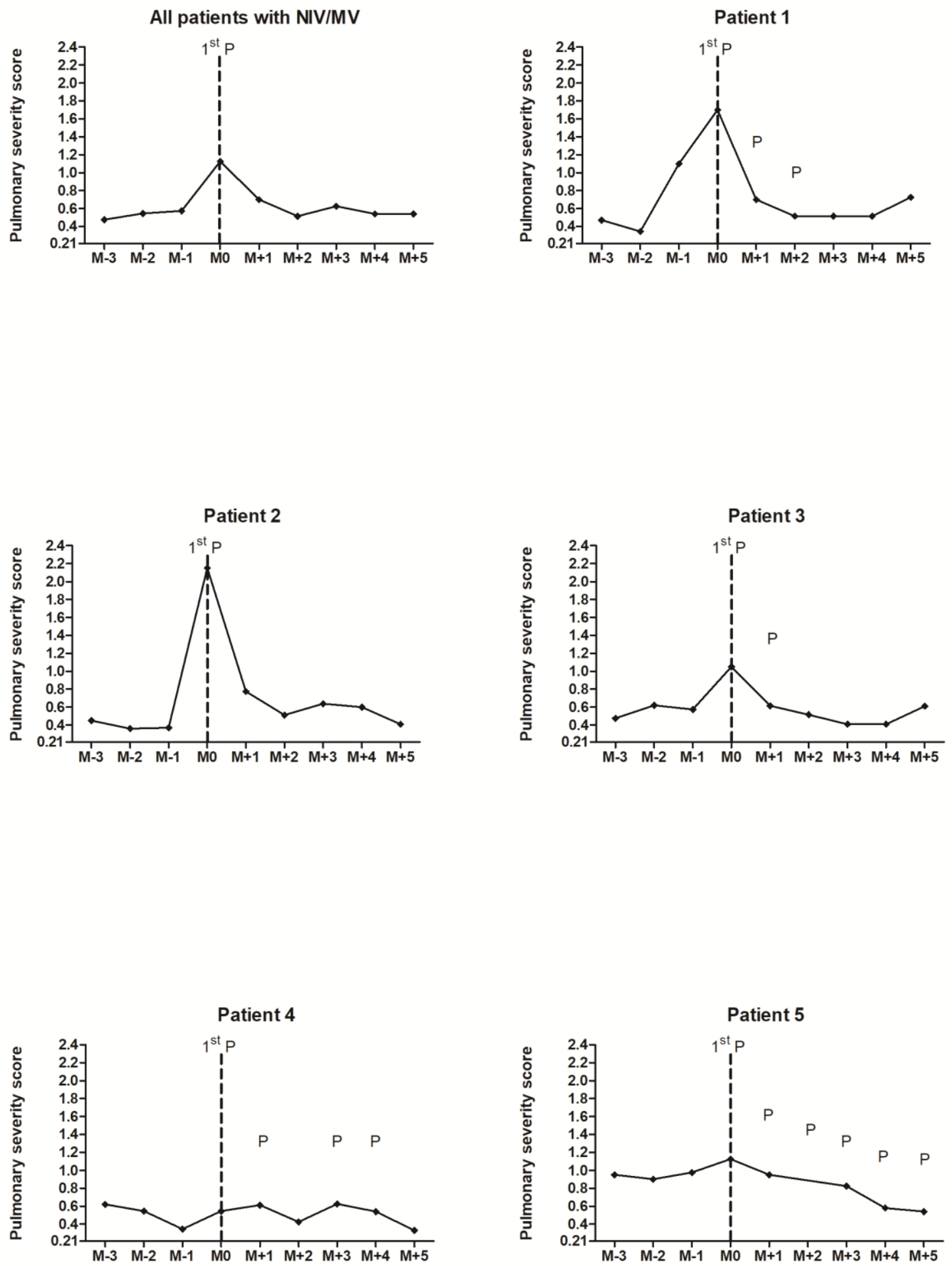

Figure 2: Evolution of the pulmonary severity scores at an individual level in infants on mechanical ventilation or non-invasive ventilation.

Legend: M: month; MV: mechanical ventilation; NIV: non-invasive ventilation; P: pulse 

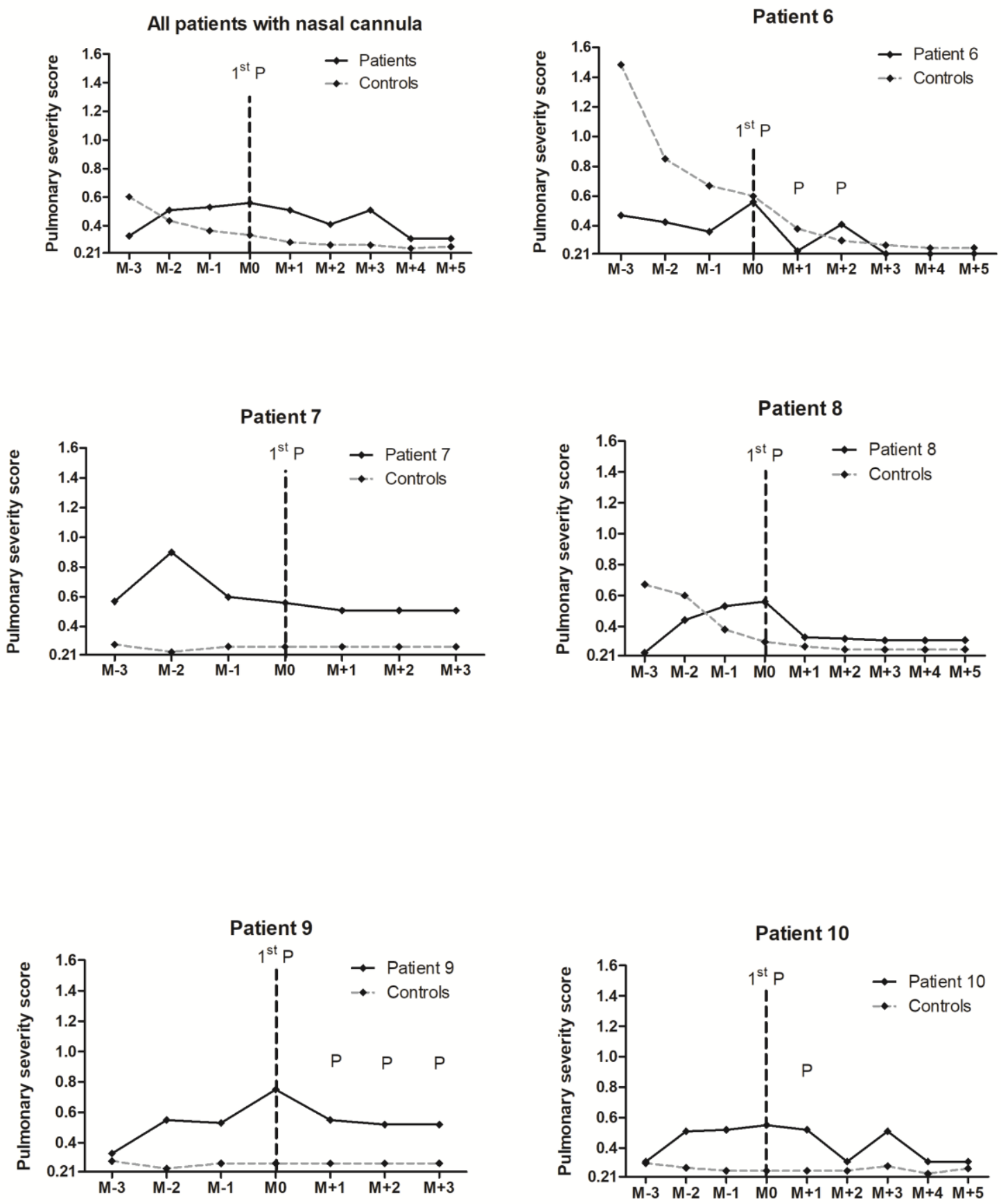

Figure 3: Evolution of the pulmonary severity scores at an individual level in infants on nasal cannula who received pulses of methylprednisolone (patients) and controls. Legend: M: month; MV: mechanical ventilation; NIV: non-invasive ventilation; P: pulse 
Table 1: Antenatal and neonatal data

\begin{tabular}{|c|c|c|c|c|}
\hline Variables & $\begin{array}{c}\text { All } \\
\mathrm{n}=16\end{array}$ & $\begin{array}{c}\text { Pulses for } \\
\text { NIV/MV } \\
\text { weaning } \\
n=5\end{array}$ & $\begin{array}{l}\text { Pulses for } \\
\text { O2 } \\
\text { weaning } \\
n=5\end{array}$ & $\begin{array}{l}\text { Controls for } \\
\mathrm{O} 2 \text { weaning } \\
\mathrm{n}=6\end{array}$ \\
\hline \multicolumn{5}{|l|}{ General characteristics } \\
\hline - Sex, $\%$ male & $8(50 \%)$ & $2(40 \%)$ & $4(80 \%)$ & $2(33 \%)$ \\
\hline \multirow{2}{*}{$\begin{array}{l}\text { Gestational age, median, } \\
\text { weeks (Q1-Q3) } \\
\text { Min- max }\end{array}$} & $26(25-28)$ & $25(25-27)$ & $29(28-31)$ & $25(25-26)$ \\
\hline & $23-31$ & 24-29 & $23-31$ & $24-28$ \\
\hline \multirow{2}{*}{$\begin{array}{l}\text { - Birth weight, median, g } \\
\text { (Q1-Q3) } \\
\text { Min- max }\end{array}$} & $\begin{array}{c}747 \\
(675-856.2)\end{array}$ & $\begin{array}{c}740 \\
(700-740)\end{array}$ & $\begin{array}{c}929(680- \\
1380)\end{array}$ & $\begin{array}{c}767.5 \\
(665-780)\end{array}$ \\
\hline & $610-1490$ & $660-1330$ & $610-1490$ & $610-835$ \\
\hline - Small for gestational age & $2(12.5 \%)$ & $1(20 \%)$ & $1(20 \%)$ & 0 \\
\hline \multicolumn{5}{|l|}{ Antenatal data } \\
\hline - Maternal smoking & $1 / 10(10 \%)$ & $0 / 2$ & $1 / 4(25 \%)$ & 0 \\
\hline - Oligoamnios & $5 / 15(33 \%)$ & 0 & $2(40 \%)$ & $3 / 5(60 \%)$ \\
\hline - Antenatal steroids & $13 / 15(87 \%)$ & $4(80 \%)$ & $4(80 \%)$ & $5 / 5(100 \%)$ \\
\hline \multicolumn{5}{|l|}{ Neonatal history } \\
\hline - Hyalin membrane disease & $13 / 15(87 \%)$ & $5(100 \%)$ & $4(80 \%)$ & $4 / 5(80 \%)$ \\
\hline - Pulmonary hypertension & 7/14 (50\%) & $2(40 \%)$ & $2(40 \%)$ & $3 / 5(60 \%)$ \\
\hline - Patent ductus arteriosus & $11 / 15(73 \%)$ & $5(100 \%)$ & $3(60 \%)$ & $3 / 5(60 \%)$ \\
\hline - $\geq 1$ sepsis & $14 / 16(87 \%)$ & $5(100 \%)$ & $4(80 \%)$ & $5 / 6(83 \%)$ \\
\hline - Necrotizing enterocolitis & 0 & 0 & 0 & 0 \\
\hline \multicolumn{5}{|l|}{ Respiratory support } \\
\hline \multirow{2}{*}{$\begin{array}{l}\text { Duration of MV, median, } \\
\text { days (Q1-Q3) } \\
\text { Min - max }\end{array}$} & $19(7-36)$ & $14(11-14)$ & $4(1-10)$ & $36(33-52)$ \\
\hline & $0.5-55$ & $6-55$ & $0.5-30$ & $32-98$ \\
\hline \multirow{2}{*}{$\begin{array}{l}\text { Duration of NIV, median, } \\
\text { days (Q1-Q3) } \\
\text { Min- max }\end{array}$} & $68.5(53-108)$ & $180(90-233)$ & $65(5-74)$ & $54(48-58)$ \\
\hline & $1-278$ & $69-278$ & $1-114$ & $32-68$ \\
\hline
\end{tabular}

NIV: non invasive ventilation. MV : mechanical ventilation. 
Table 2: Characteristics of patients, at the starting of the pulse(s) of methylprednisolone or at nine months of age in controls.

\begin{tabular}{|c|c|c|c|c|}
\hline Characteristics & $\begin{array}{c}\text { All } \\
\mathrm{n}=16\end{array}$ & $\begin{array}{c}\text { Pulses for } \\
\text { NIV/MV } \\
\text { weaning } \\
n=5\end{array}$ & $\begin{array}{c}\text { Pulses for } \\
\text { O2 weaning } \\
n=5\end{array}$ & $\begin{array}{c}\text { Controls for } \\
\text { O2 weaning } \\
n=6\end{array}$ \\
\hline $\begin{array}{l}\text { Comorbidities } \\
\text { - Heart disease (except } \\
\text { ductus arteriosus) }\end{array}$ & $4(25 \%)$ & $1(20 \%)$ & $1(20 \%)$ & $1(16 \%)$ \\
\hline - Pulmonary hypertension & $5 / 15(33 \%)$ & $2(40 \%)$ & $1 / 4(25 \%)$ & $1(16 \%)$ \\
\hline $\begin{array}{l}\text { Gastro esophageal reflux } \\
\text { treated by proton-pump } \\
\text { inhibitor }\end{array}$ & $9(56 \%)$ & $4(80 \%)$ & $3(60 \%)$ & $2(33 \%)$ \\
\hline $\begin{array}{l}\text { - Enteral feeding by } \\
\text { gastrostomy }\end{array}$ & $2(12 \%)$ & $1(20 \%)$ & $1(20 \%)$ & 0 \\
\hline $\begin{array}{l}\text { - History of Nissen } \\
\text { fundoplication }\end{array}$ & $2(12 \%)$ & $1(20 \%)$ & $1(20 \%)$ & 0 \\
\hline Respiratory drugs & $15(94 \%)$ & $5(100 \%)$ & $4(80 \%)$ & $6(100 \%)$ \\
\hline - Diuretics & $5(31 \%)$ & $3(60 \%)$ & $1(20 \%)$ & $2(33 \%)$ \\
\hline - Inhaled corticosteroids & $14(87 \%)$ & $5(100 \%)$ & $4(80 \%)$ & $5(83 \%)$ \\
\hline - Oral steroids & $12(75 \%)$ & $4(80 \%)$ & $4(80 \%)$ & $4(67 \%)$ \\
\hline - Azithromycin & $2(12 \%)$ & 0 & $1(20 \%)$ & $1(17 \%)$ \\
\hline \multicolumn{5}{|l|}{ Preventive measures } \\
\hline - Influenza vaccination & $12 / 13(92 \%)$ & $5(100 \%)$ & $5(100 \%)$ & $6(100 \%)$ \\
\hline - Palivizumab & $16(100 \%)$ & $4 / 4(100 \%)$ & $2 / 3(67 \%)$ & $6(100 \%)$ \\
\hline
\end{tabular}




\section{Supplemental Material}

Intravenous pulses of methylprednisolone for infants with severe bronchopulmonary dysplasia and respiratory support after 3 months of age

Table S1: courses of oral steroids used before the first pulse of IV methylprednisolone

\begin{tabular}{|c|c|c|c|c|c|}
\hline Patient & Molecule & $\begin{array}{l}\text { Dose } \\
\text { (mg/kg/equivalent } \\
\text { prednisolone) }\end{array}$ & $\begin{array}{l}\text { Duration } \\
\text { (days) }\end{array}$ & $\begin{array}{l}\text { Age } \\
\text { (months) }\end{array}$ & $\begin{array}{l}\text { Timing of } \\
\text { administration } \\
\text { before } 1^{\text {st }} \\
\text { pulse }\end{array}$ \\
\hline 2 & Betamethasone & N/A & 24 & 3 & M-3 \\
\hline \multirow[t]{2}{*}{3} & Betamethasone & 2 & 9 & 3.5 & M-2.5 \\
\hline & Betamethasone & 0.75 & 9 & 5 & M-1 \\
\hline \multirow[t]{2}{*}{4} & $\begin{array}{l}\text { Hydrocortisone } \\
\text { hemisuccinate }\end{array}$ & 0.5 & 9 & 2 & M-4 \\
\hline & Betamethasone & 1.25 & 8 & 3.5 & M-2.5 \\
\hline \multirow[t]{5}{*}{5} & Betamethasone & 0.8 & 5 & 1 & M-2 \\
\hline & Betamethasone & 0.8 & 19 & 1 & M-2 \\
\hline & Betamethasone & 0.8 & 9 & 2 & M-1 \\
\hline & Betamethasone & 0.8 & 4 & 2 & M-1 \\
\hline & Betamethasone & 0.3 & 30 & 2 & M-1 \\
\hline \multirow[t]{6}{*}{7} & Betamethasone & N/A & 14 & 2 & M-13 \\
\hline & Betamethasone & N/A & 16 & 9 & M-6 \\
\hline & Betamethasone & N/A & 3 & 10 & M-5 \\
\hline & Prednisolone & 2 & 10 & 11 & M-4 \\
\hline & Prednisolone & 2 & 8 & 11 & M-4 \\
\hline & Prednisolone & 2 & 8 & 12 & M-3 \\
\hline \multirow[t]{2}{*}{8} & Betamethasone & 2 & 10 & 4 & M-2 \\
\hline & Prednisolone & 2 & 15 & 5 & M-1 \\
\hline \multirow[t]{2}{*}{9} & Prednisolone & 2 & 10 & 6 & M-9 \\
\hline & Prednisolone & 2 & 10 & 13 & M-2 \\
\hline \multirow[t]{2}{*}{10} & Betamethasone & 1 & 14 & 8 & M-1 \\
\hline & Betamethasone & 1 & 7 & 9 & M-1 \\
\hline
\end{tabular}

